\title{
Flexural Strength of Provisional Crown and Fixed Partial Denture Resins both with and without Reinforced Fiber
}

\author{
Duymus $\mathrm{ZY}^{{ }^{1}}$, Karaalioglu $\mathrm{FO}^{2}$ and Suleyman $\mathrm{F}^{2}$
}

${ }^{1}$ Department of Prosthodontics, Faculty of Dentistry, Recep Tayyip Erdoğan University, Rize, Turkey

${ }^{2}$ Department of Prosthodontics, Faculty of Dentistry, Ataturk University, Erzurum, Turkey

"Corresponding author: Duymus ZY, Department of Prosthodontics, Faculty of Dentistry, Recep Tayyip Erdoğan University, 53100, Rize, Turkey, Fax: +90 46422200 00, Tel: +90 46422238 10, E-mail: zyesilz@ hotmail.com

Citation: Duymus ZY, Karaalioglu FO, Suleyman F (2014) Flexural Strength of Provisional Crown and Fixed Partial Denture Resins both with and without Reinforced Fiber. J Mater Sci Nanotechnol 2(1): 102. doi: 10.15744/2348-9812.1.302

Received Date: January 21, 2014 Accepted Date: March 7, 2014 Published Date: March 11, 2014

\begin{abstract}
Aim: The aim of this study was to evaluate the fracture strength of various provisional crown and fixed partial denture resins using an invitro test system.

Materials and Methods: Provisional crown-bridge materials (autopolymerising Poly Methyl Metacrylate (PMMA), autopolymerising Poly Ethyl Metacrylate (PEMA), bis-acryl composite resin and light cured composite resin), reinforcement materials; polyethylene fiber and glass fiber are compared. A total of 150 specimens are prepared for the flexural strength test. The specimens are divided into 5 groups according to the type of resin used (Tetric Ceram, Charisma, Dentalon Plus, TAB 2000, Protemp 3) and then each group was divided into 3 subgroups according to the type of fiber reinforcement (Construct, Fiber-splint ML). Unreinforcement specimens served as the control. Specimens are loaded in a universal testing machine until the point of fracture. The mean flexural strength (MPa) was compared using one-way analysis of variance, followed by Duncan's multiple range tests.

Results: The highest average flexural strength value was found in the Charisma with Construct fiber reinforcement (442.00 MPa). The lowest average flexural strength value was found in the Dentalon Plus without fiber reinforcement $(70.50 \mathrm{MPa})$. There was significant difference between Fiber-splint ML, Construct and control group.

Conclusion: Dentalon Plus without fiber reinforcement. There was significant difference between Fiber-splint ML, Construct and control group.

Keywords: Flexural strength; Provisional crown; Reinforced fiber
\end{abstract}

\section{Introduction}

Fabrication of provisional restorations is an important procedure in fixed prosthodontics. Provisional restorations must satisfy the requirements of pulpal protection, positional stability, occlusal function, ability to be cleansed; margin accuracy, wear resistance, strength, and esthetics [1]. The strength of a material can be a determinant of how well these requirements are met. Flexural strength, also known as transverse strength, is a measurement of the strength of a bar (supported at each end) under a static load [2]. The flexural strength test is a combination of tensile and compressive strength tests and includes elements of proportional limit and elastic modulus measurements [3]. The flexural strength of provisional materials is important, particularly when the patient must use the provisional restoration for an extended period, when the patient exhibits parafunctional habits, or when a long-span prosthesis is planned [4].

Materials commonly used to fabricate interim restorations are heat polymerising Poly Methyl Metacrylate (PMMA), autopolymerising Poly Ethyl Metacrylate (PEMA), autopolymerising Poly Methyl Metacrylate (PMMA), Bis-acryl composite resin and light cured composite resin [5-8]. They were chosen for esthetics, micro hardness, fabricating methods, economics and the other reason is fracture strengths. In patients with bruxism or patinets whose treatment plan requires long-term use of provisional restorations, provisional restorations with improved physical properties are required. Several attempts have been made to reinforce provisional Fixed Partial Dentures (FPDs). These included the use of metal wire [9] a lingual cast metal reinforcement, a processed acrylic resin interim restoration,10 and different types of fibers, e.g., carbon, polyethylene, and glass [10-14].

The concept of using fibers to reinforce an interim restoration appears to have an acceptable rate of success [14-16]. With the recent introduction of improved fiber reinforcing materials, this has become increasingly beneficial. But light cured composite resins with fiber reinforcement are not commonly used in provisional crown and bridges.

Investigations have shown that carbon fibers produced a significant increase in the flexural strength of polymers [11,17,18]; however, the black colour limits their use. Transverse strength was not improved by polyethylene fibers in the absence of surface treatment because of poor adhesion between the fibers and the polymer matrix [12]. When plasma-treated polyethylene fibers were used, a significant increase in strength was shown [19]. Silanized glass fibers are promising new materials due to their good 
sion to the polymer matrix, high aesthetic quality, and increased strength of the resulting composite [13,15,20-22]. Others have found that the position, quantity, direction of fibers, degree of adhesion between the fibers and polymer affect the degree of reinforcement.

The purpose of this study was to compare the effects of with and without two different types of fibers on the flexural strength of heat polymerising Poly Methyl Methacrylate (PMMA), auto polymerising Poly Ethyl Methacrylate (PEMA), auto polymerising Poly Methyl Methacrylate (PMMA), bis-acryl resins and light cured composite resin

\section{Materials and Methods}

Ten bar-shaped specimens with dimensions of $25 \times 2 \times 2 \mathrm{~mm}$ (American National Standards Institute/American Dental Association specification no. 27) [23] were fabricated for each material with the use of a split machined aluminium mould sandwiched between two glass slabs. The fiber-reinforced specimens were made from pre-cut 23-mm-long fibers which were wetted using the polymermonomer mix (PMMA, PEMA) and bonding agent (bis-acryl), and then these were placed in the bottom side of the mould cavity with resin applied on top of fibers. A weight of $2.5 \mathrm{~kg}$ was applied. All materials were mixed and polymerised according to the manufacturers' instructions. The specimens were stored in distilled water at $37{ }^{\circ} \mathrm{C}$ for 10 days. After this period, specimens were positioned on a flexural strength testing apparatus with $10 \mathrm{~mm}$ support separation. A 3-point bend test was carried out in a universal testing machine (Instron; M12-13667-EN) with a $10 \mathrm{kN}$ load cell at a crosshead speed of $1 \mathrm{~mm} / \mathrm{minute}$. The force was applied on specimens to the resin side. The force at fracture was recorded in MPa using testing machine software. The statistical analysis was performed using the SPSS 10.01 programme. The data was statistically analysed for differences using one-way Analysis Of Variance (ANOVA) and multiple comparisons were made using Duncan's multiple range test

\begin{tabular}{|l|l|l|}
\hline Product name & Material type & Manufacturer \\
\hline Fiber-splint ML & Glass fiber & Polydentia,CH6805;Mezzovico,Switzerland \\
\hline Construct & Polyethylene fiber & Kerr Lab, Belle de st.Claire Orange, CA 92867,USA \\
\hline Gluma Comfort Bond & Bonding agent & Heraus Kulzer Gmbh, Hanau, Germany \\
\hline Tetric ceram & Visible light curing composite & Ivoclar Vivadent AG, FL-9494, Schaan; Liechtenstein \\
\hline Charisma & Visible light curing composite & Heraus Kulzer Gmbh, Hanau, Germany \\
\hline Dentalon plus & PEMA & Heraus Kulzer Gmbh, Hanau, Germany \\
\hline TAB 2000 & PMMA & Kerr, 1717 W.Collins Ave. Orange, CA 92867 Italy \\
\hline Protemp 3 Garant & Bisacryl resin & 3M ESPE AG D-82229 Seefeld, Germany \\
\hline
\end{tabular}

\section{Results}

Table 1: Materials used

The mean flexural strengths and standard deviations are presented in Table 2. The highest average flexural strength value was found in the Charisma with Construct fiber reinforcement. The lowest average flexural strength value was found in the Dentalon Plus without fiber reinforcement. A significant difference between the Fiber-splint ML, Construct and the control group (Table 3) was observed. There was a significant increase in the specimens with reinforced fiber. Statistically, by using Duncan multiple range tests, the results revealed the flexural strength of Tetric Ceram and Charisma was significantly higher than Dentalon Plus and TAB 2000. However, there was no significant difference between the Protemp 3 and Tetric Ceram (Table 4).

\begin{tabular}{|c|c|c|c|}
\hline Materials & Fiber type & Means & SD \\
\hline \multirow{4}{*}{ Tetric ceram } & Control & 127.66 & 10.84 \\
\cline { 2 - 4 } & Construct & 426.30 & 37.77 \\
\cline { 2 - 4 } & Fiber-splint ML & 155.16 & 13.72 \\
\hline \multirow{4}{*}{ Charisma } & Control & 156.98 & 14.90 \\
\cline { 2 - 4 } & Construct & 442.00 & 60.98 \\
\cline { 2 - 4 } & Fiber-splint ML & 182.74 & 12.33 \\
\hline \multirow{4}{*}{ Dentalon Plus } & Control & 70.50 & 3.97 \\
\cline { 2 - 4 } & Construct & 191.00 & 20.12 \\
\cline { 2 - 4 } & Fiber-splint ML & 88.14 & 13.36 \\
\hline \multirow{4}{*}{ TAB 2000 } & Control & 98.28 & 8.14 \\
\cline { 2 - 4 } & Construct & 160.52 & 22.08 \\
\cline { 2 - 4 } & Fiber-splint ML & 124.00 & 18.06 \\
\hline \multirow{2}{*}{ Protemp 3 } & Control & 126.74 & 19.47 \\
\cline { 2 - 4 } & Construct & 351.65 & 29.30 \\
\cline { 2 - 4 } & Fiber-splint ML & 229.24 & 28.05 \\
\hline
\end{tabular}

Table 2: Mean flexural strengths and standard deviations 


\begin{tabular}{|c|c|c|c|}
\hline Fiber & 1 & 2 & 3 \\
\hline Control & $116.03^{\mathrm{c}}$ & & \\
\hline Fiber-splint ML & & $155.86^{\mathrm{b}}$ & \\
\hline Construct & & & $307.12^{\mathrm{a}}$ \\
\hline
\end{tabular}

Table 3: Mean flexural strengths for fiber-reinforcement groups

\begin{tabular}{|c|c|c|c|}
\hline Material & $\mathbf{1}$ & $\mathbf{2}$ & $\mathbf{3}$ \\
\hline Dentalon Plus & $116.55^{\mathrm{a}}$ & & \\
\hline TAB 2000 & $127.60^{\mathrm{a}}$ & & \\
\hline Protemp 3 & & $227.61^{\mathrm{b}}$ & \\
\hline Tetric ceram & & $236.37^{\mathrm{b}, \mathrm{c}}$ & $236.37^{\mathrm{b}, \mathrm{c}}$ \\
\hline Charisma & & & $247.61^{\mathrm{c}}$ \\
\hline
\end{tabular}

Table 4: Mean flexural strengths and standard deviations for resins

In this study, five provisional crown materials and two fibers were evaluated for flexural strength. While flexural strength values obtained in laboratory under static load may not reflect the conditions found in the oral environment, it is useful to compare provisional materials tested in a controlled situation. Strength values may be a useful predictor of clinical performance.

The use of fibers to reinforce a provisional restoration seems to have an acceptable success rate [16]; because of the recent advances in the production of improved fiber-reinforcing materials [24].

Numerous investigators have confirmed the reinforcing effect of fibers on different polymer types [11-22,24,25]. This is in agreement with the results of this study, which revealed that the majority of tested fibers increased the flexural strength of provisional restoration resins. The explanation for this increase was the transfer of stress from the weak polymer matrix to the fibers that have a high tensile strength [16]. The stronger adhesion between the fiber and the matrix, the greater the strengthening effect [21]. In fact, the presence of poorly bonded fibers, to which little load is transferred, can be almost equivalent to voids [26].

\section{Discussion}

One approach to increase the adhesion of fibers to a polymer matrix is resin impregnation of fibers before application. An effective impregnation process allows the resin to come into contact with surface of every fiber. Wetting the fibers with a monomer has been a commonly used method. However, although the monomer increases the adhesion of fibers to the matrix, it may impair other properties because of the residual monomer. The pre-impregnated fiber-construct used in the present study was developed to overcome this problem and compare with the non pre-impregnated e-glass fiber.

The degree of fiber adhesion to the polymer matrix also differs according to the type of fiber used. Several surface treatments of polyethylene fibers have attempted to solve this problem, including plasma spraying, chemical, flame, and radiation treatments. Construct consists of pre-impregnated silanized plasma treated polyethylene fibers. The present study showed that there was a significant difference between the reinforcing effect of Construct polyethylene fibers and Fiber-splint ML glass fiber. The improved performance of the Construct product may be due to the use of silane, as well as plasma treatment to increase the degree of adhesion of the polyethylene fibers to the resin.

The results revealed better strengthening effects for all resins tested with Construct rather than with Fiber-splint ML. The present study showed that there was a difference in the results of the flexural strength test. This difference may be caused by Fiber-splint ML glass fiber that is not pre-impregnated.

When using reinforced provisional resin materials clinically, it may be beneficial to choose a combination that, although prone to fracturing, is held together by intact fibers. This might prevent catastrophic failure and may decrease patient discomfort and unscheduled appointments. Both unreinforced and Fiber-splint ML reinforced specimens showed undesirable complete separation. With the remaining groups, the fibers were intact, and the fracture stopped at the fiber location, suggesting that use of these fibers may be beneficial in reinforcing fixed provisional restorations, which may be used for extended periods.

\section{Conclusion}

The Within limitations of this invitro study, the following points were discovered:

1. Visible light curing composites display higher flexural strength than other provisional restorations.

2. The use of fibers is an effective method of increasing flexural strength of provisional restoration resin.

\section{References}

1) Shillingburg HT, Hobo S, Whitsett LD, Brackett SE. Fundamentals of Fixed Prosthodontics, 3 ed. Chicago: Quintessence Publishing Co. 1997: pp. $225-227$.

2) Anusavice, Phillips (1996) Science of dental materials, 10th edn, WB Saunders, Philadelphia, USA.

3) Craig R (2002) Restorative dental materials, 11th edn, St. Louis: Mosby, USA.

4) Haselton DR, Diaz-Arnold AM, Vargas MA (2002) Flexural strength of provisional crown and fixed partial denture resins. J Prosthet Dent 87: 225-8. 
5) Davidoff SR (1982) Heat- processed acrylic resin provisional restorations: an in-office procedure. J Prosthet Dent 48: 673-5.

6) . Phillips RW (1973) Skinner's science of dental materials, 9th edn, W.B aunders Co, Philadelphia, USA.

7) Christensen GJ (2003) The fastest and best provisional restorations. J Am Dent Assoc 134: 637-9.

8) Driscoll CF, Woolsey G, Ferguson WM (1991) Comparison of exothermic release during polymerisation of four materials used to fabricate interim restorations. J Prosthet Dent 65: 504-6. J Prosthet Dent 65: 504-6.

9) Vallittu PK, Vojtkova H, Lassila VP (1995) Impact strength of denture polymethyl methacrylate reinforced with continuous glass fibers or metal wire. Acta Odontol Scand 53: 392-6.

10. Emtiaz S, Tarnow DP (1998) Processed acrylic resin provisional restoration with lingual cast metal framework. J Prosthet Dent 79:484-8.

11. Yazdanie N, Mahood M (1985) Carbon fiber acrylic resin composite: an investigation of transverse strength. J Prosthet Dent 54 : $543-7$.

12. Vallittu PK (1997) Ultra-high-modulus polyethylene ribbon as reinforcement for denture polymethyl methacrylate: a short communication. Dent Mater 13:381-2. 13. Aydin C, Yilmaz H, Caglar A (2002) Effect of glass fiber reinforcement on the flexural strength of different denture base resins. Quintessence Int 33: 457-63.

14. Pfeiffer P, Grube L (2003) In vitro resistance of reinforced interim fixed partial dentures. J Prosthet Dent 89:170-4.

15. Hamza TA, Rosenstiel SF, El-Hosary MM, Ibraheem RM (2006) Fracture resistance of fiber-reinforced PMMA interim fixed partial dentures. J Prosthodont 15: $223-8$.

16. Nohrström T, Vallittu P, Yli-Urpo A (2000) The effect of placement and quantity of glass fibers on the fracture resistance of interim fixed partial dentures. Int J Prosthodont 13: 72-8.

17. Schreiber CK (1971) Polymethyl methacrylate reinforced with carbon fibers. Br Dent J 130: 29-30.

18. Larson WR, Dixon DL, Aquilino SA, Clancy JM (1991) The effect of carbon graphite fiber reinforcement on the strength of provisional crown and fixed partial denture resins. J Prosthet Dent 66: 816-20.

19. Ramos V Jr, Runyan DA, Christensen LC (1996) The effect of plasma treated polyethylene fiber on the fracture strength of polymethyl methacrylate. J Prosthet Dent 76: 94-6.

20. Kolbeck C, Rosentritt M, Behr M, Lang R, Handel G (2002) In vitro study of fracture strength and marginal adaptation of polyethylene-fiber-reinforced- composite versus glass-fiber-reinforced-composite fixed partial dentures. J Oral Rehabil 29: 668-74.

21. Solnit GS (1991) The effect of methyl methacrylate reinforcements with silane treated and untreated glass fibers. J Prosthet Dent 66: 310-4.

22. Vallittu PK (1994) Acrylic resin-fiber composite-Part II: The effect of polymerization shrinkage of polymethyl methacrylate applied to fiber roving on transverse strength. J Prosthet Dent 71: 613-7.

23. ANSI/ADA 27 (1993) Direct filling resins. American National Standards Institute, American Dental Association, Chicago, USA.

24. Vallittu PK (1999) Flexural properties of acrylic resin polymers reinforced with unidirectional and woven glass fibers. J Prosthet Dent 81: $318-26$.

25. Lassila LV, Vallittu PK (2004) The effect of fiber position and polymerization condition on the flexural properties of fiber-reinforced composite. J Contemp Dent Pract 15: 14-26.

26. Kanie T, Arikawa H, Fujii K, Ban S (2002) Mechanical properties of reinforced denture base resin: the effect of position and the number of woven glass fibers. Dent Mater J 21: 261-9.

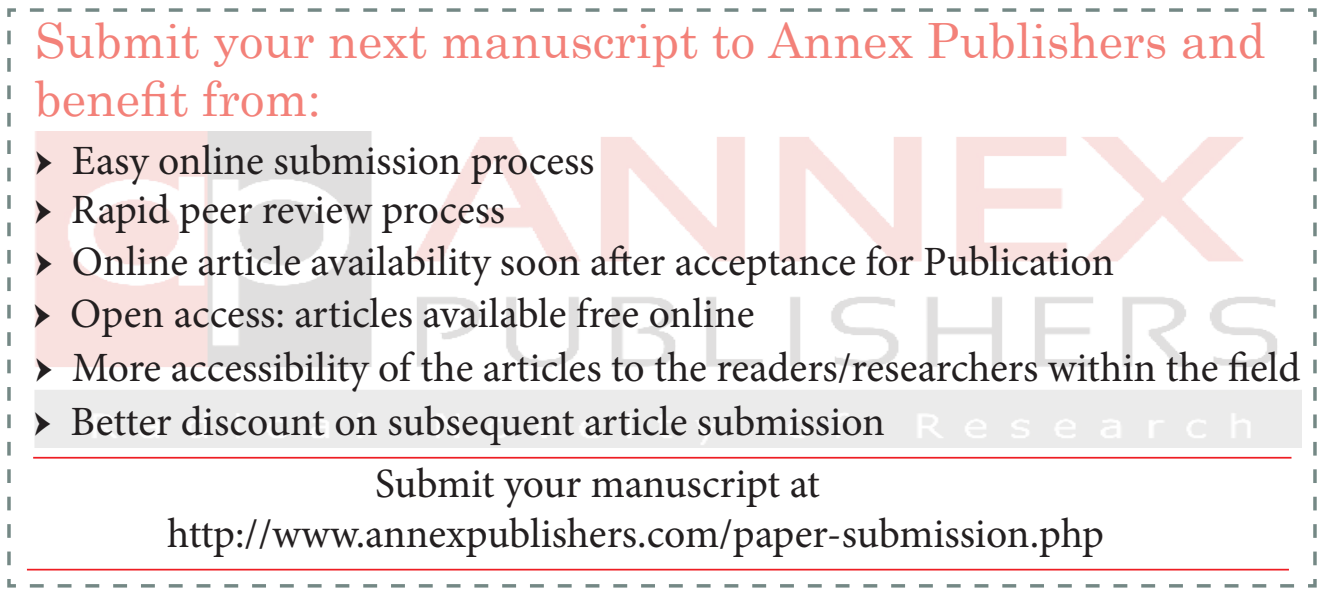

